\title{
Chemokine CCL24 promotes the growth and invasiveness of trophoblasts through ERK1/2 and PI3K signaling pathways in human early pregnancy
}

\author{
Hui Li ${ }^{1}$, Yu-Han Meng ${ }^{1}$, Wen-Qing Shang ${ }^{1}$, Li-Bing Liu ${ }^{1}$, Xuan Chen ${ }^{1}$, Min-Min Yuan ${ }^{1}$, \\ Li-Ping Jin ${ }^{1,2}$, Ming-Qing $\mathrm{Li}^{1,2,3}$ and Da-Jin $\mathrm{Li}^{1,3}$ \\ ${ }^{1}$ Laboratory for Reproductive Immunology, Hospital of Obstetrics and Gynecology, Fudan University, \\ Zhao Zhou Road 413, Shanghai 200011, China, ${ }^{2}$ Shanghai Key Laboratory of Female Reproductive \\ Endocrine Related Diseases, Shanghai 200011, China and ${ }^{3}$ NPFPC Key Laboratory of Contraceptive Drugs \& \\ Devices, Shanghai Institute of Planned Parenthood Research, Shanghai, China
}

Correspondence should be addressed to M-Q Li; Email: mqli@fudan.edu.cn or to D-J Li; Email: djli@shmu.edu.cn

\begin{abstract}
Chemokine CCL24, acting through receptor CCR3, is a potent chemoattractant for eosinophil in allergic diseases and parasitic infections. We recently reported that CCL24 and CCR3 are co-expressed by trophoblasts in human early pregnant uterus. Here we prove with evidence that steroid hormones estradiol (E), progesterone (P), and human chorionic gonadotropin (hCG), as well as decidual stromal cells (DSCs) could regulate the expression of CCL24 and CCR3 of trophoblasts. We further investigate how trophoblast-derived CCL24 mediates the function of trophoblasts in vitro, and conclude that CCL24/CCR3 promotes the proliferation, viability and invasiveness of trophoblasts. In addition, analysis of the downstream signaling pathways of CCL24/CCR3 show that extracellular signal-regulated kinases (ERK1/2) and phosphoinositide 3-kinase (PI3K) pathways may contribute to the proliferation, viability and invasiveness of trophoblasts by activating intracellular molecules Ki67 and matrix metallopeptidase 9 (MMP9). However, we did not observe any inhibitory effect on trophoblasts when blocking c-Jun N-terminal kinase (JNK) or p38 pathways. In conclusion, our data suggests that trophoblast-derived CCL24 at the maternal-fetal interface promotes trophoblasts cell growth and invasiveness by ERK1/2 and PI3K pathways. Meanwhile, pregnancy-related hormones (P and hCG), as well as DSCs could up-regulate CCL24/CCR3 expression in trophoblasts, which may indirectly influence the biological functions of trophoblasts. Thus, our results provide a possible explanation for the growth and invasion of trophoblasts in human embryo implantation. Reproduction (2015) 150 417-427
\end{abstract}

\section{Introduction}

Embryo implantation is a complex process which requires not only the growth and differentiation of villi, but also trophoblasts invade into maternal uterine arteries so as to establish sufficient blood supply for the conceptus (Timeva et al. 2014). When fetal-derived villi contact with maternal decidua, a subpopulation of trophoblasts located at the tips of anchoring villi undergo proliferation and differentiation, and develop into invasive extravillous trophoblasts (EVTs). Finally, EVTs infiltrate into decidual spiral arteries to remodel the vessel walls (Chen etal. 2012). The entire process is precisely regulated by modulators at the maternal-fetal interface; for example, decidual immune cells (DICs), DSCs, female steroid hormones and cytokines (Paiva et al. 2011, Oreshkova et al. 2012). However, failure to achieve this process may result in pregnant complications, such as abortion, preeclampsia, fetal growth restriction (FGR), gestational trophoblastic diseases, and so on (Kwak-Kim et al. 2010, Kinoshita et al. 2012).
Chemokines, whose principle role is orchestrating immune response in the body, are a large family of chemotactic cytokines (Zlotnik \& Yoshie 2012). CCL24 is a member of CCL chemical family. Because of its similar effect with eotaxin-1 (CCL26) and eotaxin-3 (CCL28) on attracting eosinophils, it is also called eotaxin-2 (Zhebrun et al. 2014). CCR3 is the only receptor of CCL24 (Zlotnik \& Yoshie 2012). However, other CCL chemokines such as CCL5, CCL7, CCL8, CCL12, CCL13, CCL15, CCL26 and CCL28 share the receptor with CCL24, even if they have different affinities (Vinader \& Afarinkia 2012). CCR3 is mainly presented on eosinophils, and is also found on basophils, monocytes, Th2 lymphocytes, epithelial cells as well as airway smooth muscles (Zhebrun et al. 2014). Thus, CCL24 is considered a contributor to kinds of atopic disorders, parasitic infections and numerous systemic diseases (Owczarek et al. 2010, Kinoshita et al. 2012). 
The maternal-fetal interface is a specific chemokine-rich environment and several chemokines have been found there (He et al. 2012, Wallace et al. 2013). Our previous work provided evidence that trophoblasts are an important source of CCL24 in human early pregnant uterus (Li et al. 2013). At the same time, CCR3 is detected on human villi and trophoblast cell line HTR8/SVneo (Chau et al. 2013, Li et al. 2013). However, whether trophoblasts have a self-regulation through CCL24/CCR3 axis and what the downstream mechanisms are still largely unknown. The aim of the present study was to investigate the effect of CCL24/CCR3 on the biological behaviors of trophoblasts, and to find out possible signaling pathways in this process. Meanwhile, we identified local factors at the maternalfetal interface that may influence the expression of CCL24/ CCR3 by trophoblasts

\section{Materials and methods}

\section{Tissue collection, isolation and culture of trophoblasts and DSCs}

The study was approved by the Ethical Committee of the Obstetrics and Gynecology Hospital, Fudan University. All tissue samples were obtained with the consent of patients.

Villi and deciduas were collected from first-trimester pregnant women (age 20-35 years, gestational age 6-9 weeks) who chose termination for no medical reasons. Before their curettage operations, their blood tests, including steroid hormones, and ultrasound examination of the fetuses were normal. In addition, those who were overweight, had the habit of smoking or drinking, had or acute or chronic diseases were excluded. After the curettage operations, villi ( $n=10$, age: $27 \pm 6.77$ years, gestational age: $7 \pm 1.41$ ) were soon collected and stored in $10 \%$ buffered formalin at $4{ }^{\circ} \mathrm{C}$ for wax embedding. For primary culture, sterile villi ( $n=242$, age: $26 \pm 2.01$ years, gestational age: $8 \pm 0.49)$ or deciduas $(n=26$, age: $24 \pm$ 3.75 years, gestational age: $7 \pm 1.53$ ) samples were immediately put into ice-cold high D-glucose DMEM (HG-DMEM; Gibco Grand Island, NY, NY, USA), with 1\% penicillin and streptomycin in the medium. Tissues were transported to the laboratory within $30 \mathrm{~min}$, and then trophoblasts and DSCs were isolated according to our previous procedures ( $\mathrm{Li}$ et al. 2010). These methods supplied about $85 \%$ cytokeratin-positive purified trophoblasts, and about $98 \%$ vimentin-positive and cytokeratinnegative DSCs. Cells were cultured with HG-DMEM plus $10 \%$ BSA (Hyclone, Logan, UT, USA), and incubated at $37^{\circ} \mathrm{C}$ in a $5 \% \mathrm{CO}_{2}$ incubator.

\section{Immunohistochemistry for detecting the expression of CCR3 on villi}

Paraffin sections $(5 \mu \mathrm{m})$ of villi were dehydrated in graded ethanol. After blocking the endogenous peroxidase activity by $3 \% \mathrm{H}_{2} \mathrm{O}_{2}$ for 15 min, samples were incubated with goat anti-human CCR3 antibody $(15 \mu \mathrm{g} / \mathrm{ml}, \mathrm{R} \& \mathrm{D}$ Systems, Minneapolis, MN, USA), or goat IgG isotype in a humid chamber overnight at $4{ }^{\circ} \mathrm{C}$. All sections were washed three times with PBS, and then overlaid with peroxidase-conjugated anti-goat IgG (Golden Bridge International, Inc, Beijing, China). The color reaction was developed with 3,3-diaminobenzidine (DAB), and then counterstained with hematoxylin. Results were observed by Olympus BX51+DP70 microscope (Olympus, Tokyo, Japan).

\section{Flow Cytometry for detecting CCR3 on trophoblasts}

Flow cytometry was applied to evaluate the purity of primary cultured trophoblasts and the expression of CCR3 on trophoblasts. Cytokeratin 7 (CK7) is a protein that specifically expressed in epithelial tissues, and is used as a maker of trophoblast in villi (Li et al. 2010). Freshly isolated trophoblasts were gently washed with PBS, and then mixed with mouse anti-human CK7-FITC MAB (BD, Franklin Lakes, NJ, USA) and CCR3-APC MAB (Biolegend, San Diego, CA, USA). Isotypic control antibodies were used. After incubation in darkness for $30 \mathrm{~min}$ at room temperature, cells were analyzed immediately by a flow cytometer (FACS Calibur, BD). All samples were analyzed by flow cytometry three times and the experiment was repeated eight times.

In order to evaluate whether DSCs influence the expression of CCR3 on trophoblasts, we co-cultured trophoblasts and DSCs $\left(1 \times 10^{5}\right.$ cells/well) (the ratios of DSC:trophoblats were $1: 3,1: 2,1: 1$ or $2: 1$ respectively) in 12-well plates for $48 \mathrm{~h}$, then CCR3 expression on trophoblasts in co-culture unit was analyzed by flow cytometry.

In addition, we treated trophoblasts $\left(2 \times 10^{5}\right.$ cells/ well) with $17 \beta-E_{2}\left(E, 10^{-8} \mathrm{M}\right)$, progesterone $\left(P, 10^{-8} \mathrm{M}\right)$, or human chorionic gonadotropin (hCG, $5 \mathrm{kU} / \mathrm{l}$ ) for $48 \mathrm{~h}$. Then, the supernatant was collected for detecting the level of CCL24, and cells were harvested for CK7 and CCR3 staining by flow cytometry.

\section{ELISA for detecting the level of CCL24}

ELISA was taken to evaluate the level of CCL24 that secreted by trophoblasts after treatment with E, P or hCG for $48 \mathrm{~h}$. Cell culture supernatant was collected as previously mentioned, and centrifuged to remove cellular debris, and then stored at $-80^{\circ} \mathrm{C}$. The ELISA for CCL24 (R\&D Systems) was accomplished following the manufacture's instruction. The sensitivity of this product is $2.5 \mathrm{pg} / \mathrm{ml}$.

\section{BrdU cell proliferation assay and MTT assay}

Trophoblasts were plated at the density of $1 \times 10^{4}$ cells/well in 96-well flat-bottom plates. Before 
treatment, trophoblasts were starved for $12 \mathrm{~h}$, with HG-DMEM that included $1 \%$ BSA as culture medium. Then, cells were stimulated by recombinant human CCL24 (rhCCL24, 0.1, 1, 10 or $100 \mathrm{ng} / \mathrm{ml}$ ), anti-CCL24 neutralizing antibody (a-CCL24, 0.08, 0.4, 2 or $10 \mu \mathrm{g} / \mathrm{ml}$ ), anti-CCR3 neutralizing antibody (a-CCR3, $0.32,1.6,8$ or $40 \mu \mathrm{g} / \mathrm{ml}$ ) or vehicle for $48 \mathrm{~h}$. All of those reagents were purchased from R\&D Systems. Then, BrdU cell proliferation assay (Millipore, Billerica, MA, USA) was used to evaluate the proliferation ability of trophoblasts according to the manufacturer's instruction. Each experiment was performed in triplicate, and repeated six times.

The MTT (3-[4,5-dimethylthiazol-2-yl]-2,5 diphenyl tetrazolium bromide) assay is a colorimetric assay for assessing cell viability. It is based on the conversion of MTT into formazan crystals, which has a purple color (van Meerloo et al. 2011). We treated trophoblasts with rhCCL24, a-CCL24 or a-CCR3 (all concentrations were the same with BrdU assay) for $48 \mathrm{~h}$, then washed the plates with sterile PBS, and added $180 \mu \mathrm{l}$ of conditioned medium plus $20 \mu \mathrm{l}$ of $5 \mathrm{mg} / \mathrm{ml}$ MTT solution per well. From then on, plates were conserved or handled in dark. After $4 \mathrm{~h}$ of cell culture in the incubator, we gently removed culture fluid, added $150 \mu$ of DMSO to dissolve purple crystals, stirred the plates in a gyratory shaker for $5 \mathrm{~min}$, and finally read the plates at $490 \mathrm{~nm}$ within $1 \mathrm{~h}$. Each experiment was performed in triplicate, and repeated six times.

\section{Matrigel invasion assay}

The transwell plates (24-well, pore size $8 \mu \mathrm{m}$ ) for invasion assay were purchased from Becton Dickinson Discovery Lab-ware. First of all, the inner bottoms of upper chambers were coated with $15 \mu \mathrm{l} /$ well matrigel solution (the work concentration was $1.5 \mathrm{mg} / \mathrm{ml}$; BD), then we placed the plates in humid $37^{\circ} \mathrm{C}$ incubator for matrigel solidification. Four hours later, HG-DMEM conditioned medium $(600 \mu \mathrm{l} /$ well $)$ with rhCCL24 $(0,0.1,1,10$ or $100 \mathrm{ng} / \mathrm{ml})$ was added into the lower chambers of the plates. At the same time, trophoblasts $\left(2 \times 10^{5}\right.$ cells, $200 \mu \mathrm{l}$ medium $)$ were seeded directly into the upper chambers. The plates were incubated for $48 \mathrm{~h}$ at $37^{\circ} \mathrm{C}$ in a $5 \% \mathrm{CO}_{2}$ incubator, so cells could migrate through the matrigel membrane. After incubation, cells in the upper chambers were removed using cottontipped swabs, while other cells which had invaded through the matrigel membrane and reached the outer surface of upper chambers were carefully handled. We fixed cells with $10 \%$ formalin for $10 \mathrm{~min}$ and then stained them with hematoxylin for $15 \mathrm{~min}$. After rinsing the upper chambers twice with distilled water, results were observed under the Olympus BX51+DP70 microscope (Olympus, Tokyo, Japan). We counted the number of cells that had passed through the membrane and clung to the bottom side of the upper chambers.
Each experiment was performed in triplicate and repeated four times.

\section{Treatment with MAPK/ERK1/2, PI3K, JNK or p38 pathway inhibitor}

Trophoblasts were treated with signaling inhibitors for MAPK/ERK1/2 (U0126, 10uM), PI3K (LY294002, $10 \mu \mathrm{M})$, JNK (SP600125, $10 \mu \mathrm{M})$ or p38 (SB203580, $10 \mu \mathrm{M})$ with or without rhCCL24. All inhibitors were purchased from Cell Signal Technology (Danvers, MA, USA). First, trophoblasts were seeded into plates and treated with rhCCL24. We plated cells $1 \times 10^{4} /$ well into 96 -well flatbottom plates for viability and proliferation assays, and added rhCCL24 to the medium at the concentration of $1 \mathrm{ng} / \mathrm{ml}$. For invasion, ELISA or flow cytometry assay, we seeded $5 \times 10^{5}$ cells/well in 24-well flat-bottom plates and stimulated cells by $10 \mathrm{ng} / \mathrm{ml}$ rhCCL24. Forty-eight hours later, the viability, proliferation and invasiveness of trophoblasts were detected as procedures previously described.

At the same time, cell culture supernatant was collected for analyzing the concentration of matrix metalloproteinase-9 (MMP9) and metallopeptidase inhibitor-1 (TIMP1). In the present study, we tested the level of MMP9 and TIMP-1 to investigate roles of CCL24 in trophoblast invasion regulation. Human MMP9 and TIMP-1 ELISA Kit were purchased from Shanghai Excell Biology, Inc (Shanghai, China). The experiments were performed by following the manufacture's instruction. The sensitivity of the two products was $30 \mathrm{pg} / \mathrm{ml}$.

In addition, the intracellular $\mathrm{Ki} 67$ and $\mathrm{Bcl}-2$ of trophoblasts were detected by flow cytometry. We treated trophoblasts with ERK and PI3K inhibitors as previously mentioned, and then analyzed the effect of inhibitors on Ki67 and Bcl-2 expression. Trophoblasts were washed with cold PBS, treated with FOXP3 Fix/Perm Buffer Set (Biolegend) by following instruction, stained with Ki67PE MAB or Bcl-2-FITC MAB (BD) in dark for $30 \mathrm{~min}$, and finally analyzed cells by flow cytometry.

\section{Statistical analysis}

All values are expressed as mean \pm s.D. Statistical analysis was performed using t-test or one-way ANOVA with Statistical Package for the Social Sciences Software version 11.5. Differences were considered as statistically significant if $P<0.05$.

\section{Results}

\section{Human first-trimester trophoblasts express CCR3 and DSCs promote it expression}

To determine the expression and localization of CCR3 at trophoblasts, we performed immunohistochemistry for paraffin-embedded villi. From Fig. 1A, an abundant 
A

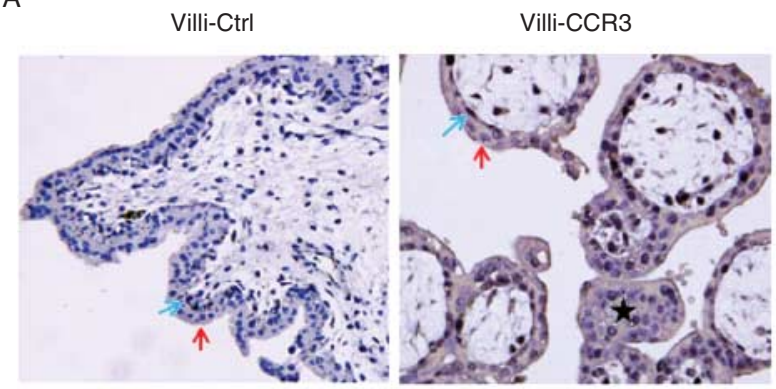

B

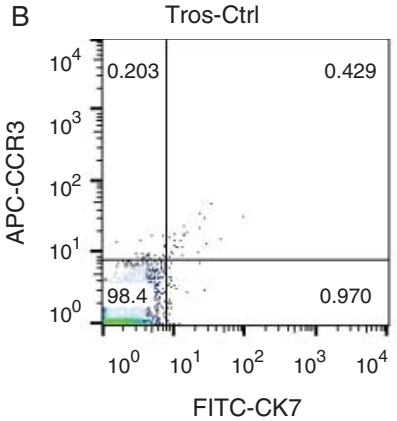

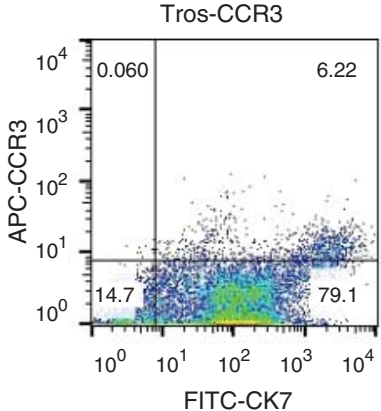

D

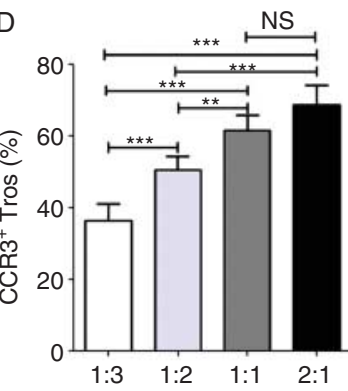

Figure 1 Human first-trimester trophoblasts express CCR3 and DSCs promote it expression. (A) Immunohistochemical location of CCR3 in villi. The CCR3 protein was observed at the trophoblast layer as well as the cell column. Original magnification: $\times 400$. (B) Flow cytometry results showed the expression of CCR3 on freshly isolated trophoblasts. We used CK7 as a marker of trophoblasts. The purity of primary cultured trophoblasts was more than $85 \%$, and CCR3 was detected on the surface of trophoblasts. (C and D) DSCs promote the expression of CCR3 on trophoblasts. After trophoblasts were directly co-cultured with DSCs $\left(1 \times 10^{5}\right.$ cells/well) (the ratios of DSCs: trophoblasts were 1:3, 1:2, 1:1 and 2:1) for 48 h, the level of CCR3 on trophoblasts increased significantly. The CK7-negative population represented DSCs, and trophoblasts were CK7-positive. DSCs, decidual stromal cells; Tros, trophoblasts. The blue arrows indicate the cytotrophoblasts, the red arrows indicate the syncytiotrophoblasts, and the black star indicates the trophoblastic cell column. ${ }^{* *} P<0.01$ and ${ }^{* * *} P<0.001 ; \mathrm{NS}$, no statistical difference.

expression of CCR3 was observed at the trophoblast layer as well as the cell column which is formed by trophoblasts. Besides, CCR3 protein was detected at both the cytomembrane and cytoplasm of trophoblasts. Further, we primary cultured trophoblasts and investigated the level of CCR3 on trophoblasts. CK7, a maker of epithelial cells, was chosen to identify trophoblasts, because trophoblasts are fetal originated epithelial cells. The purity of freshly isolated trophoblasts reached $85 \%$ as we tested it by flow cytometer. Meanwhile, the positive rate of CCR3 on primary cultured $\mathrm{CK}^{+}$trophoblasts was $(8.79 \pm 1.85) \%$ (Fig. 1B).

At the maternal-fetal interface, the complicated crosstalk between fetal derived trophoblasts and maternal derived DSCs has been illustrated before. Trophoblasts were recognized to directly contact with DSCs ( $\mathrm{Li}$ et al. 2010,2011). Thus, we speculated that DSCs might influence the biological function of trophoblasts by regulating the expression of CCR3 on trophoblasts. We then co-cultured trophoblasts with DSCs in different proportion (the ratios of DSC:trophoblats were 1:3, 1:2, $1: 1$ or 2:1), and detected the level of CCR3 on CK $7^{+}$ trophoblasts. From Fig. 1C and D, even when the ratio of DSCs and trophoblasts were 1:3, DSCs could significantly promote CCR3 expression. Along with the increase of DSCs proportion in the co-culture system, CCR3 level in trophoblasts was gradually increased.
It suggests that DSCs up-regulate CCR3 expression in trophoblasts in a cell number-dependent manner.

\section{E, P and hCG regulate CCL24/CCR3 expression of trophoblasts}

During human early pregnancy, sex steroid hormones $\mathrm{E}, \mathrm{P}$ and hCG are at high concentrations in peripheral blood and uterus. Moreover, these hormones are the most vital factors to control trophoblast growth and invasion during embryo implantation and placentation (Szekeres-Bartho et al. 2009, Chen et al. 2011, Park \& Yang 2011). To study whether E, P and hCG modulate trophoblasts through regulating the expression of $\mathrm{CCL} 24$ and CCR3, we treated freshly isolated trophoblasts with these hormones in vitro. As shown in Fig. 2A and B, hCG $(5 \mathrm{kU} / \mathrm{l})$ significantly increased the level of CCL24 $(P<0.05)$ as well as CCR3 $(P<0.001)$ that expressed by trophoblasts when compared to control group. We also observed a promoting effect of $\mathrm{P}\left(10^{-8} \mathrm{M}\right)$ on CCR3 $(P<0.01)$, but we did not find any notable increase of CCL24. In addition, our data showed that $E\left(10^{-8} \mathrm{M}\right)$ was able to reduce the secretion of $C C L 24$ by trophoblasts $(P<0.01)$, while there was no effect on CCR3 expression. These results suggest that steroid hormones $\mathrm{E}, \mathrm{P}$ and $\mathrm{hCG}$ regulate the expression of CCL24 and CCR3 of trophoblasts, but in a complex way. 

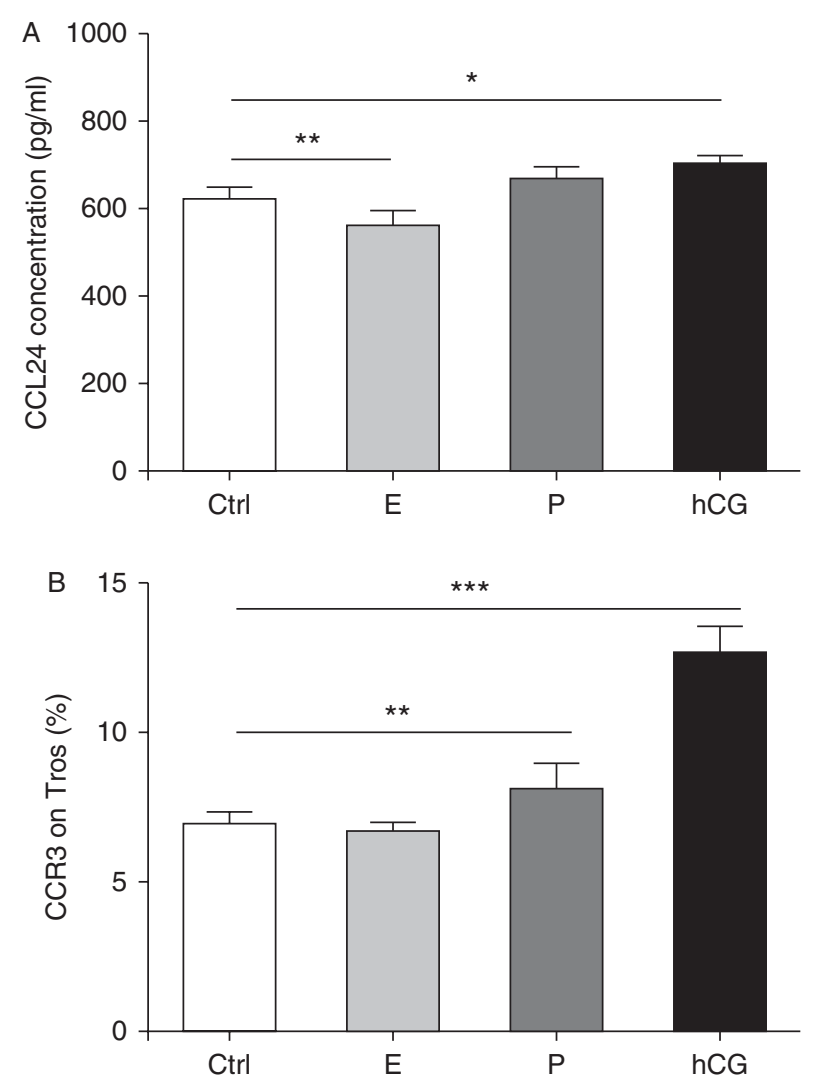

Figure $2 \mathrm{E}, \mathrm{P}$ and hCG regulate CCL24/CCR3 expression of trophoblasts. The expression of CCL24 (A) and CCR3 (B) by trophoblasts after they were treated with $\mathrm{E}, \mathrm{P}$ and hCG. Freshly isolated trophoblasts were treated with $\mathrm{E}\left(10^{-8} \mathrm{M}\right), \mathrm{P}\left(10^{-8} \mathrm{M}\right)$, and hCG ( $5 \mathrm{kU} / \mathrm{l})$ for $48 \mathrm{~h}$, then the supernatant was tested by ELISA and the cells were harvested for flow cytometry. Ctrl, control; E, $17 \beta$-estradiol; $P$, progesterone; hCG, human chorionic gonadotropin; ${ }^{*} P<0.05$, ${ }^{* *} P<0.01$ and ${ }^{* * *} P<0.001$ compared to the control group.

\section{CCL24 promotes the proliferation, viability and invasiveness of trophoblasts}

Based on our finding that trophoblasts secrete chemokine CCL24 and also express receptor CCR3, we further investigated whether CCL24 could impact the biological behaviors of trophoblasts. We performed BrdU proliferation assay, MTT assay and matrigel invasion assay to evaluate the effect of CCL24 on the proliferation ability, viability and invasiveness of trophoblasts respectively. Our results showed that rhCCL24 significantly promoted the proliferation and viability of trophoblasts at the dose of $1 \mathrm{ng} / \mathrm{ml}$ (Fig. 3A and B, $P<0.01$ ), which is approximately equal to the concentration we detected from the supernatant of trophoblasts (Li et al. 2013). Meanwhile, rhCCL24 stimulated the invasiveness of trophoblasts at the concentrations from 1 to $100 \mathrm{ng} / \mathrm{ml}$, but the maximum effect was observed at $10 \mathrm{ng} / \mathrm{ml}(P<0.001$, Fig. $3 C$ and D). In contrast, either a-CCL24 or a-CCR3 was able to eliminate the stimulatory effect of rhCCL24 on trophoblasts. Overall, these data suggest that CCL24 is an important promoter for the growth and invasiveness of trophoblasts in human early pregnancy.

\section{CCL24 enhances the proliferation and viability of trophoblasts through MAPK/ERK1/2 and PI3K signaling pathways}

To further study the potential signaling pathways downstream of CCL24/CCR3 axis, we treated trophoblasts with signaling inhibitors for MAPK/ERK1/2, PI3K, JNK or p38 pathways, with or without rhCCL24. Then we repeated BrdU proliferation assay and MTT assay to evaluate the proliferation and viability of trophoblasts, and test the expression of proliferation-associated and apoptosisassociated molecules in cells. As shown, we observed that rhCCL24 increased the proliferation of trophoblasts in the control groups (Fig. 4A, $P<0.01$ ), which confirmed our previous results (Fig. 3A). In addition, inhibitors for ERK1/2 and PI3K significantly inhibited the proliferation of trophoblasts, when compared with the control group that have not been stimulated by rhCCL24 (Fig. 4A, $P<0.01$ ). Meanwhile, in the presence of rhCCL24, the two inhibitors also decreased the proliferation of trophoblasts (Fig. 4A, $P<0.001)$. However, the same inhibitory effect was not observed in JNK or p38 inhibitor treatment groups, even though rhCCL24 increased the proliferation ability of trophoblasts in both groups (Fig. 4A).

Since we have figured out that MAPK/ERK $1 / 2$ and PI3K pathways are downstream signalings of CCL24/CCR3 in trophoblasts, the inhibitors for ERK1/2 and PI3K were again added to analyze their role in regulating the viability of trophoblasts. From the results, treatment with rhCCL24 undoubtedly increased the viability of trophoblasts in the control groups (Fig. 4B, $P<0.05$ ). The inhibitor for PI3K, but not for ERK1/2, decreased the viability of cells (Fig. 4B, $P<0.001$ ). Moreover, the two inhibitors could decrease the effect of rhCCL24 when compared with the control group, but a greater role was observed in the PI3K inhibitor group (Fig. 4B).

We further analyzed which molecules are mediated by the MAPK/ERK $1 / 2$ pathway and PI3K pathway in trophoblast proliferation. Protein Ki67 is a cellular marker for proliferation, while Bcl-2 family contains antiapoptotic proteins (including $\mathrm{Bcl}-2, \mathrm{BCl}-\mathrm{xL}$, and $\mathrm{BCl}-\mathrm{w}$ ) as well as pro-apoptotic proteins (including Bax, Bad, Bak and Bok) (Cory \& Adams 2002). They are associated with or may be necessary for cell growth and survival (Ali et al. 2012). Therefore, we measured the level of intracellular $\mathrm{Bcl}-2$ and Ki67 proteins after treatment trophoblasts with the two inhibitors. Interestingly, we found that about $80 \%$ of trophoblasts were Ki67 positive (Fig. 4C and D), but the level of $\mathrm{Bcl}-2$ in trophoblasts was hardly detected (Fig. 4E and $\mathrm{F}$ ). In addition, rhCCL24 could increase the expression of Ki67 (Fig. 4C and D, $P<0.001$ ), but no significant difference was observed for $\mathrm{Bcl}-2$ protein (Fig. 4E and F). After treatment with inhibitors for ERK and PI3K, the level of intracellular Ki67 of trophoblasts 

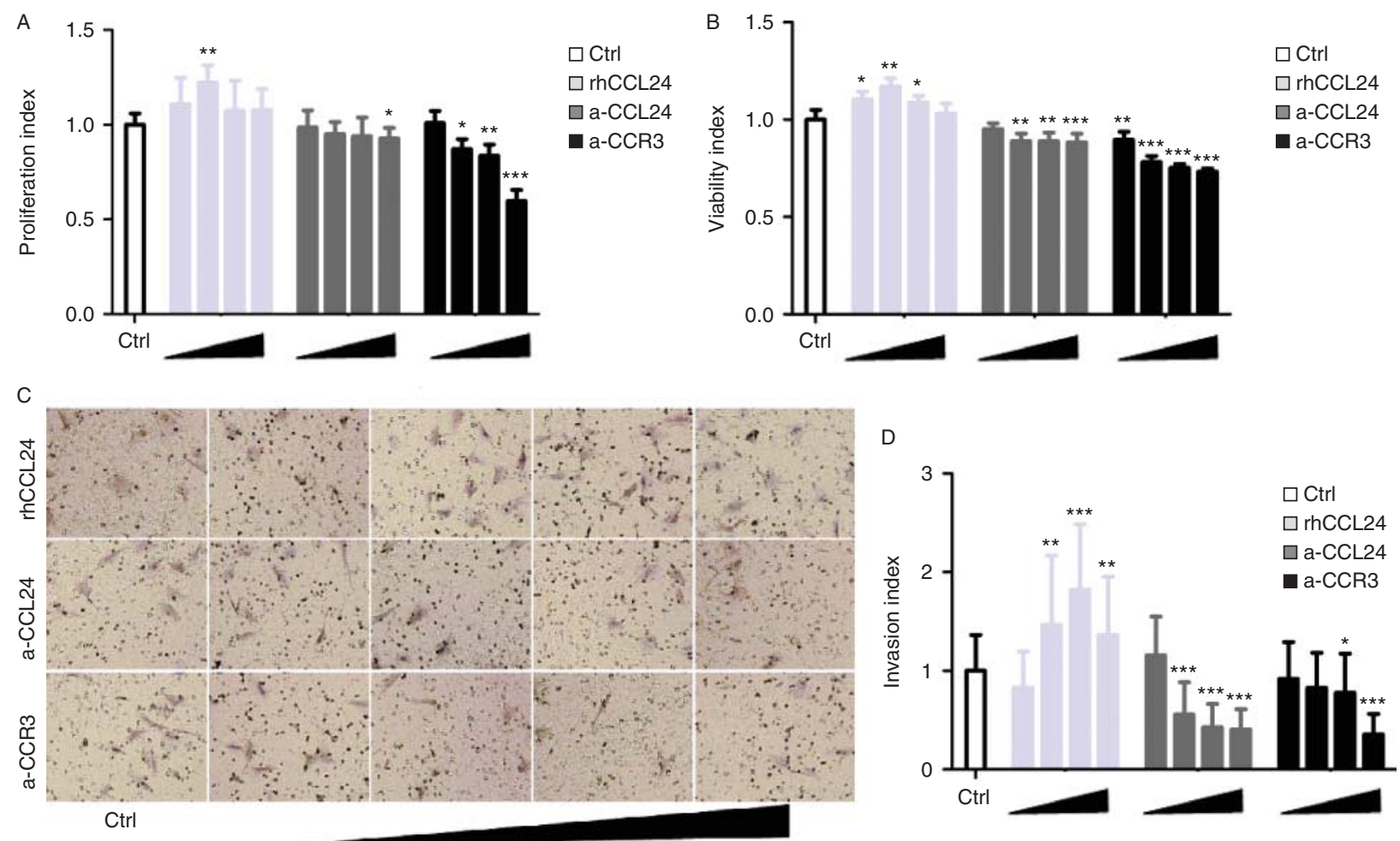

Figure 3 CCL24 promotes the proliferation, viability and invasiveness of trophoblasts. Trophoblasts were treated with recombinant human CCL24 ( $\mathrm{rCCCL} 24 ; 0.1,1,10$ or $100 \mathrm{ng} / \mathrm{ml}$ ), anti-CCL24 neutralizing antibody (a-CCL24; 0.08, 0.4, 2 or $10 \mu \mathrm{g} / \mathrm{ml}$ ), or anti-CCR3 neutralizing antibody (a-CCR3; 0.32, 1.6, 8 or $40 \mu \mathrm{g} / \mathrm{ml}$ ) for $48 \mathrm{~h}$. (A) BrdU cell proliferation assay was performed to examine the proliferation of trophoblasts. We set the OD value of control group as 1, and calculated the proliferation index of treatment groups. (B) MTT assay was used to detect the viability of trophoblasts. The result was shown as viability index. (C and D) Matrigel invasion assay was performed to examine the invasiveness of trophoblasts. (C) Representative pictures show the trophoblasts which invaded through the matrigel coated transwells; original magnification: $\times 400$. (D) The relative numbers of trophoblasts which have invaded through transwells. We set the total number of control group as 1 , and calculated the invasion index. Ctrl, control; ${ }^{*} P<0.05,{ }^{* *} P<0.01$ and ${ }^{* * *} P<0.001$ compared to control group.

decreased significantly (Fig. 4C and D, $P<0.05$ ). Meanwhile, the two inhibitors also prohibited the promoting effect of rhCCL24 (Fig. 4C and D, $P<0.05$ ). However, we did not see any apparent regulation to $\mathrm{Bcl}-2$ by the two inhibitors (Fig. 4E and F).

Due to the extremely low expression of $\mathrm{Bcl}-2$ in trophoblasts, we then tested two other $\mathrm{Bcl}-2$ family members: anti-apoptotic protein $\mathrm{BCl}-\mathrm{xL}$ and pro-apoptotic protein Bax. The expressions of $\mathrm{BCl}-\mathrm{xL}$ and $\mathrm{Bax}$ in trophoblasts were much higher than $\mathrm{BCl}-2$, with the positive rates about 40 and $20 \%$ respectively (Supplementary Figure 1, see section on supplementary data given at the end of this article ). When we treated trophoblasts with the inhibitor for ERK1/2 pathway, we observed up-regulating expressions of $\mathrm{Bax}$ and $\mathrm{BCl}-\mathrm{xL}$. However, we did not observe any regulation by rhCCL24 to Bcl-xL and Bax (Supplementary Figure 1, see section on supplementary data given at the end of this article).

Collectively, CCL24 could up-regulate the proliferation and viability of trophoblasts through MAPK/ERK1/2 and PI3K signaling pathways. Among this process, Ki67, but not Bcl-2, may be an important participator.

\section{CCL24 promotes MMP9 production and enhances the invasiveness of trophoblasts through PI3K signaling pathway}

Given that CCL24/CCR3 regulate the proliferation and viability of trophoblasts through MAPK/ERK $1 / 2$ and PI3K pathways, we investigated whether they play roles in regulating the invasiveness of trophoblasts. MMP family is involved in the breakdown of extracellular matrix, yet the TIMP family are natural inhibitors of the MMP members (Yamamoto et al. 2015). Both of them are important participators in the process of cell invasion. Similarly, we treated trophoblasts with the inhibitors for ERK1/2 and PI3K, with or without the presence of rhCCL24, and then repeated matrigel invasion assay. RhCCL24 promoted the invasiveness of trophoblasts (Fig. 5A, $P<0.01$ ), which was consistent with our previous results. The inhibitor for $\mathrm{PI} 3 \mathrm{~K}$ was able to inhibit trophoblast invasion (Fig. 5A, $P<0.001$ ) even when compared in the rhCCL24 treatment groups (Fig. 5A, $P<0.001$ ). However, there was no notable regulation performed by $\mathrm{PI} 3 \mathrm{~K}$ inhibitor. 
A

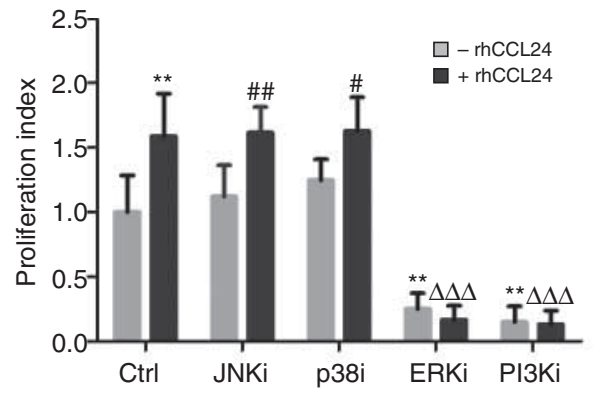

B

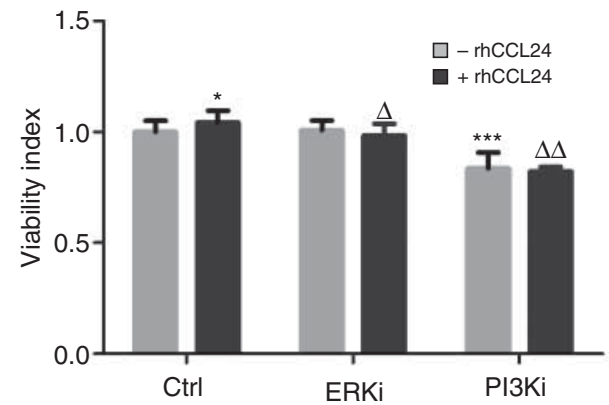

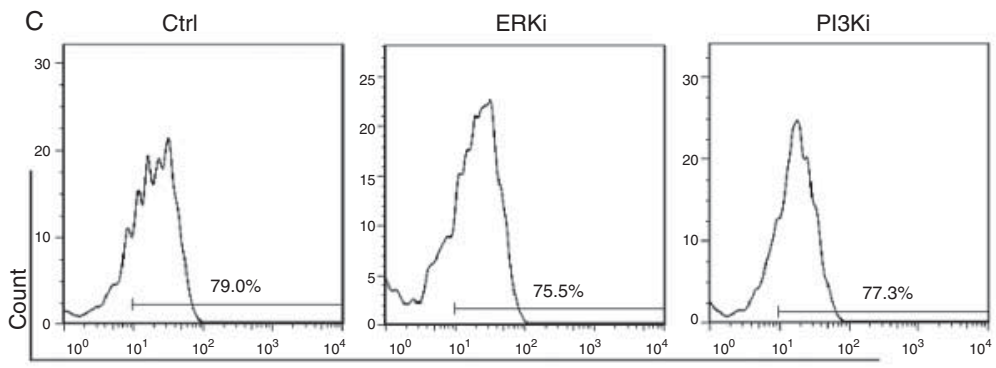
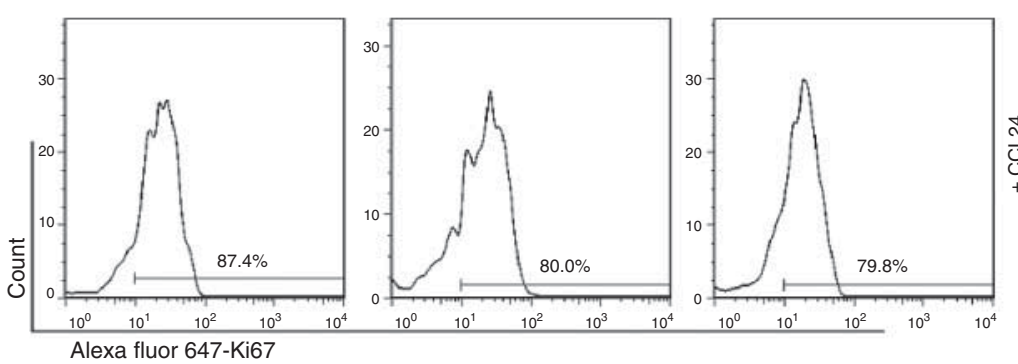

D

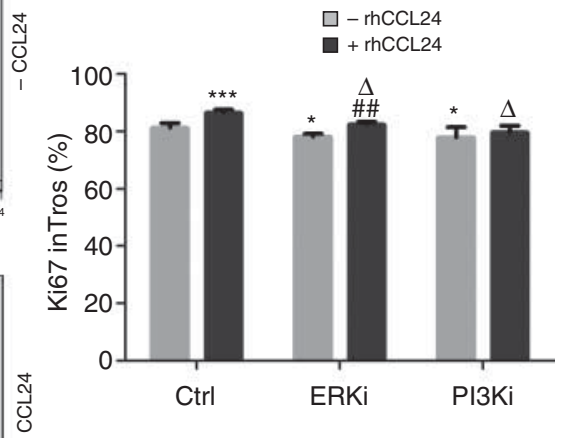

E

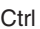

ERKi
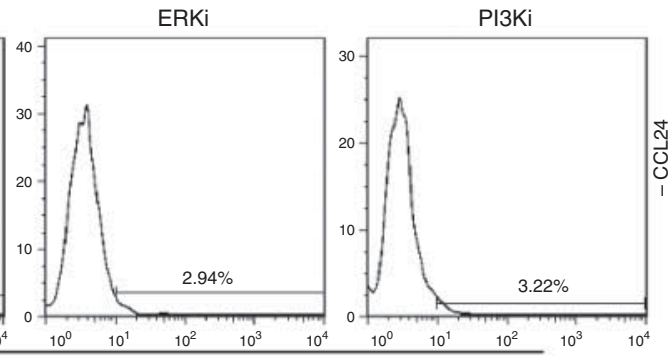

FITC-BCl-2
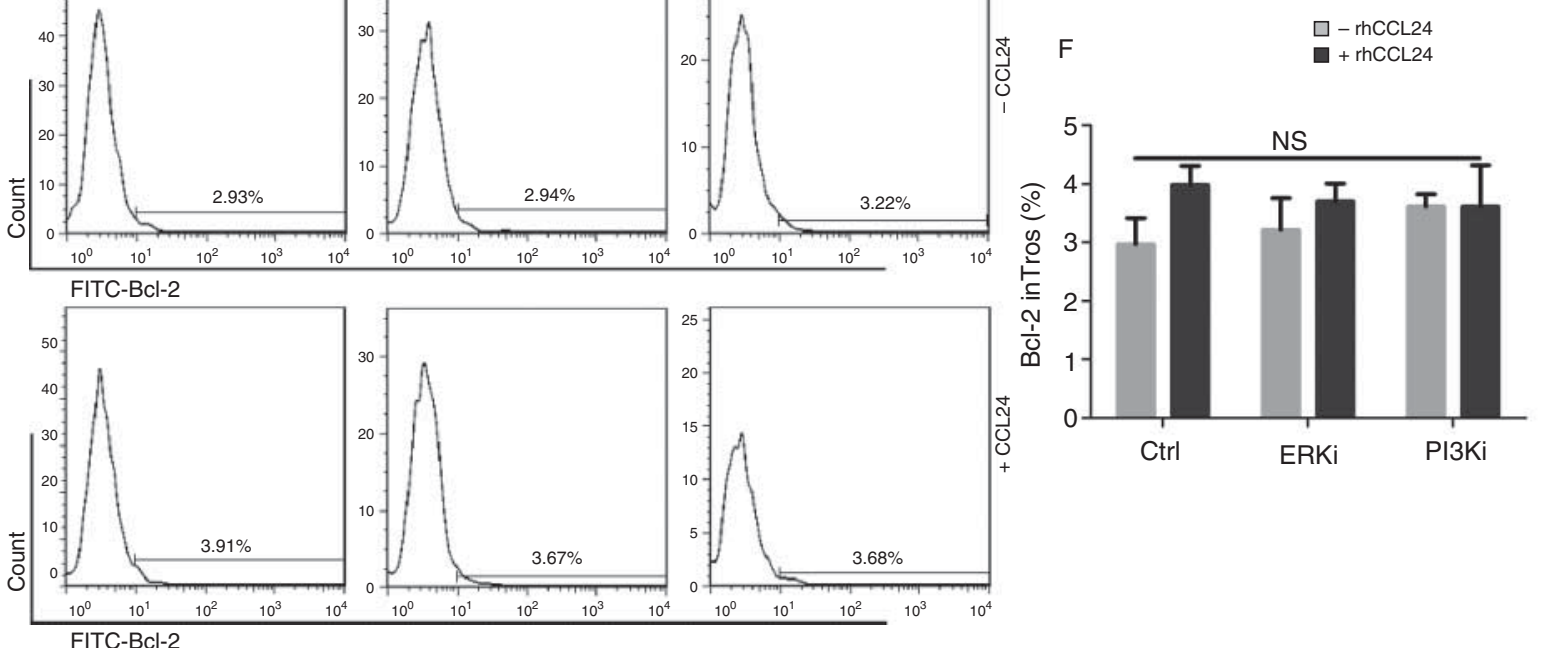

Figure 4 CCL24 enhances the proliferation and viability of trophoblasts through MAPK/ERK1/2 and PI3K signaling pathways. (A) CCL24 promotes the proliferation of trophoblasts through MAPK/ERK1/2 and PI3K pathways. The inhibitors for MAPK/ERK1/2 $(10 \mu \mathrm{M})$, PI3K $(10 \mu \mathrm{M})$, JNK (10 $\mu \mathrm{M})$ or p38 $(10 \mu \mathrm{M})$ pathways, with or without rhCCL24 $(1 \mathrm{ng} / \mathrm{ml})$, were added to trophoblasts for $48 \mathrm{~h}$. We repeated the BrdU cell proliferation assay and calculated the proliferation index. (B) The PI3K inhibitor reduces the viability of trophoblasts. Trophoblasts were treated with inhibitors for MAPK/ERK1/2 or PI3K for $48 \mathrm{~h}$, and MTT assay was performed to evaluate the viability of cells. After the same treatment, the intracellular level of Ki67 (C and D) and Bcl-2 (E and F) in trophoblasts were tested by flow cytometry. ERKi, inhibitor for MAPK/ERK1/2 (U0126); PI3Ki, inhibitor for MAPK/ERK1/2 (LY294002). Data were shown as mean \pm S.D. NS, no significant difference. ${ }^{*} P<0.05, * * P<0.01$ and ${ }^{* * *} P<0.001$ compared to the control group; ${ }^{\sharp} P<0.05$ and ${ }^{\# \#} P<0.01$ compared in the same inhibitor treatment groups, but with or without rhCCL24; ${ }^{\triangle} P<0.05, \triangle \triangle P<0.01$ and $\triangle \triangle \triangle P<0.001$ compared to the rhCCL24 control group. 

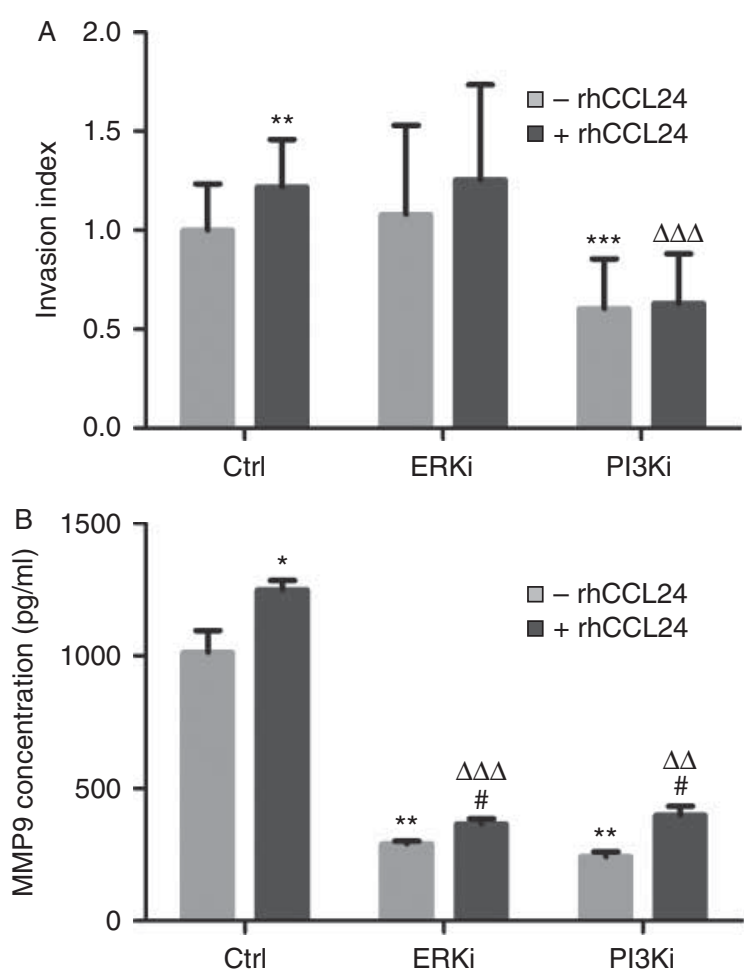

C

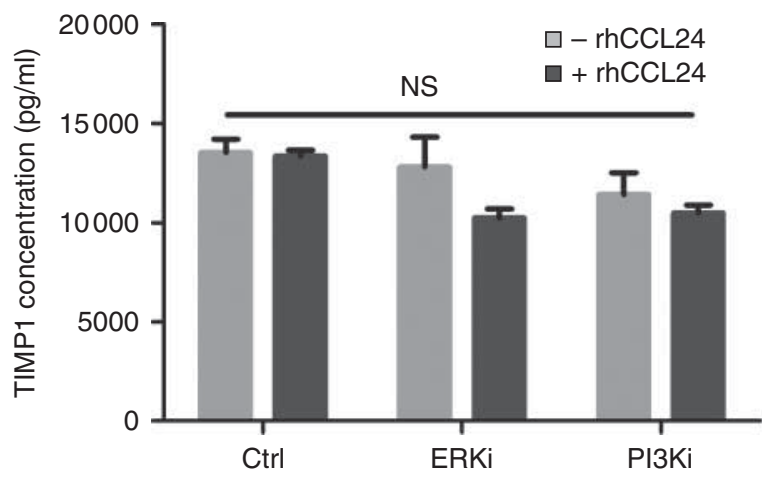

Figure 5 CCL24 promotes MMP9 production and enhances the invasiveness of trophoblasts through PI3K signaling pathway. (A) The PI3K inhibitor, but not MAPK/ERK1/2 inhibitor, reduces the invasiveness of trophoblasts. Trophoblasts were treated with the inhibitors for MAPK/ ERK1/2 $(10 \mu \mathrm{M})$ and PI3K $(10 \mu \mathrm{M})$, with or without rhCCL24 $(10 \mathrm{ng} / \mathrm{ml})$. Matrigel invasion assay was repeated. The result was presented by invasion index. Cell culture supernatant from inhibitors treatment trophoblasts were collected, and tested for the concentration of MMP9 and TIMP1 by ELISA. (B) and (C) show the concentration of MMP9 and TIMP1 in the supernatant respectively. Data are shown as mean \pm s.D. NS, no significant difference. ${ }^{*} P<0.05,{ }^{* *} P<0.01$ and ${ }^{* * *} P<0.001$ compared to control group; ${ }^{\sharp} P<0.05$ compared in the same inhibitor treatment groups, but with or without rhCCL24; $\triangle \triangle_{P}<0.01$ and $\triangle \triangle \triangle P<0.001$ compared to the rhCCL24 control group.

TIMP-1 and MMP9 are well-known for their role in mediating the breakdown of extracellular matrix, and they are important regulators for cell invasion. Thus, we collected the supernatant of inhibitors-treated trophoblasts, and measured the concentration of TIMP-1 and MMP9 by ELISA. Our results showed that trophoblasts secreted high level of TIMP-1 and MMP9, the concentrations reached at $(13530.29 \pm 807.50) \mathrm{pg} / \mathrm{ml}$ and $(1011.46 \pm 82.77) \mathrm{pg} / \mathrm{ml}$ respectively (Fig. 5C and B). RhCCL24 significantly increased the level of soluble MMP9 in the supernatant (Fig. 5B, $P<0.05$ ). Meanwhile, inhibitors for both ERK1/2 and PI3K were able to reduce the secretion of MMP9 by trophoblasts (Fig. 5B, $P<0.001$ ), and they also decreased the stimulatory effect of rhCCL24. However, rhCCL24 and two inhibitors did not influence TIMP-1 level (Fig. 5C, $P>0.05$ ).

\section{Discussion}

During the first trimester of human pregnancy, successful embryo implantation and placentation are essential requirements for the establishment of normal gestation. Trophoblasts, as the main component of chorionic villi, play a leading role in the process. Therefore, the behaviors of trophoblasts, such as the proliferation, viability and invasion are vitally important (Chen et al. 2012). Even though a lot of researches have been done to study the biological changes of trophoblasts in embryo implantation, the mechanism has not been fully illustrated yet. In the present work, we demonstrated that trophoblastderive CCL24 could regulate the proliferation ability, viability and invasiveness of trophoblasts through MAPK/ ERK1/2 and PI3K signaling pathways. At the same time, the local factors of maternal-fetal interface like steroid hormone $\mathrm{E}, \mathrm{P}$, and hCG as well as DSCs influence the expression of CCL24/CCR3 by trophoblasts, which may finally regulate the biological behaviors of trophoblasts and embryo implantation.

Chemokines are a group of chemotactic cytokines, which usually act to induce the migration and activation of leukocytes in immune responses (Vinader \& Afarinkia 2012). However, the human early pregnant uterus is also a chemokine abundant environment. Trophoblasts, DSCs, DICs and decidual epithelial cells are the sources of various chemokines (Li et al. 2011, Erlebacher 2013). Among these, trophoblasts are recognized as the most important origination of chemokines; for instance, chemokine CXCL6, CXCL8, CXCL12, CCL14, and CCL4 (Jovanovic et al. 2010, Li et al. 2011, Zhang et al. 2013). We had reported that trophoblasts secrete chemokine CCL24 (Li et al. 2013). In the present study, we further verified the existence of receptor CCR3 on the surface of trophoblasts, which is in agreement with one previous report that demonstrated the expression of CCR3 on trophoblast cell line HTR8/SVneo (Chau et al. 2013). These observations gave a clue that trophoblasts probably exert self-regulation in the local uterus, while the CCL24/CCR3 axis maybe involved in this process.

In the process of embryo implantation, once trophoblasts attach and penetrate into decidua, they emerge in an entirely specific environment. Fetal-derived trophoblasts form an extensive crosstalk with maternal-derived cells such as DSCs and DICs, and they are also exposed 
to high concentration of steroid hormones $\mathrm{E}, \mathrm{P}$ and hCG (Szekeres-Bartho et al. 2009, Chen et al. 2011, Park \& Yang 2011). DSCs do not secrete CCL24, but they induce trophoblasts to secrete a higher level of CCL24 (Li et al. 2013). In this study, we found that DSCs also up-regulated CCR3 expression on trophoblasts. Thus, DSCs may facilitate the function of CCL24/CCR3 axis in trophoblasts by increasing the expression of both chemokine and receptor. However, the molecular mechanism needs to be further explored. Trophoblast can also influence the maternal immune system during pregnancy by expressing soluble and cell surface molecules, such as HLA-G (Rizzo et al. 2007, Carosella et al. 2008, Oreshkova et al. 2012) and IDO (Munn et al. 1998). These molecules limit the proliferation and activation of T, APC (antigen presenting cell) and NK cells in decidua. CCL24 secreted by trophoblasts may also involved in immune regulation at the maternal-fetal interface by dialogue with $\mathrm{CCR} 3{ }^{+} \mathrm{DIC}$, which needs to be further studied.

Steroid hormones E, P, hCG are the key regulating factors in pregnancy (Cha et al. 2012). Both E and hCG are synthesized by trophoblasts, and hCG can maintain the production of $\mathrm{P}$ by the corpus luteum (Chen et al. 2012). P and hCG are classically known for their stimulatory roles in trophoblasts invasion and functional differentiation (Halasz \& Szekeres-Bartho 2013). However, the role of $\mathrm{E}$ in regulating trophoblasts remains unclear. The receptor of estrogen ER $\alpha$ was found in differentiating cytotrophoblast cells of term placenta (Bukovsky et al. 2003). Nevertheless, it was proposed that $\mathrm{E}$ might not have significant impact on trophoblasts based on the fact that $\mathrm{E}$ deficiency usually did not result in fetal abnormalities (Chen et al. 2012). Chen et al. (2011) found that hCG stimulated the migration of cells but did not affect cell number, high dose of $\mathrm{P}$ inhibited the migration of trophoblast cell line HTR8/SVneo as well as the number of cells, but $E$ had no effect. However, our results showed that hCG and $\mathrm{P}$ increased the expression of CCL24 or CCR3 by trophoblasts, while E had an opposite function.

One cause of the difference may be that cell line HTR8/SVneo cannot display the real features of normal trophoblasts. It is also possible that $\mathrm{E}, \mathrm{P}$ and hCG influence trophoblasts through other ways. All of this evidence indicates that steroid hormones could directly regulate the expression of CCL24 and CCR3 by trophoblasts. On the other hand, the receptors of $\mathrm{E}, \mathrm{P}$, and hCG exist in most uterine tissue compartments. They regulate the function of endometrial stromal cells (ESCs) and DSCs soon after decidualization occurs (Cha et al. 2012, Chen et al. 2012). In pregnant uterus, trophoblasts, DSCs, and steroid hormones form a very complicated dialogue interface. We have reported that these steroid hormones could promote the growth of DSCs through up-regulating CCR3 expression on DSCs (Li et al. 2013). DSC is also an important stimulator for CCL24 and CCR3 expression in trophoblasts. Therefore, steroid hormones might also up-regulate CCL24/CCR3 expression of trophoblasts by strengthening dialogue between DSC and trophoblast.

Chemokines regulate the main events that occurred at the maternal-fetal interface, such as the endometrium decidualization, vessel remodeling and immune tolerance (Kuang et al. 2009, Godbole et al. 2011). Moreover, chemokines were also proven to modulate the biological functions of trophoblasts, and finally regulate the process of embryo implantation. CXCL12 (stromal cell-derived factor-1, SDF-1/) has an antiapoptotic effect on human trophoblasts (Jaleel et al. 2004), and CXCL16 is able to induce the proliferation and invasion of first-trimester human trophoblasts in an autocrine manner (Huang et al. 2006). Similarly, the present work showed that CCL24 promotes the proliferation ability, viability and invasiveness of trophoblasts, which implied a beneficial role of CCL24/CCR3 in embryo implantation.

In eosinophils, the function of CCL24/CCR3 axis can be exerted by activating MAPK/ERK1/2, PI3K, and p38 signaling pathways (Shamri et al. 2013). Meanwhile, these signaling are universally associated with regulating cell's growth, survival and invasiveness. For instance, CCL2 enhances the survival and invasiveness of endometrial stromal cells by activating MAPK/ERK1/2 and PI3K pathways (Li et al. 2012); IL-25 promotes the proliferation of DSCs by activating Akt and JNK pathways (Wang et al. 2014); JNK and p38 pathways were also proved to inhibit the growth and induce the apoptosis of human colorectal carcinoma cells (Zhang et al. 2014). Therefore, in the present study, the role of MAPK/ERK $1 / 2$, $\mathrm{PI} 3 \mathrm{~K}, \mathrm{JNK}$ and p38 signaling pathways were analyzed when trophoblasts were treated with CCL24. Our data suggest that when the proliferation, viability and invasiveness of trophoblasts are induced by CCL24/ CCR3 axis, the MAPK/ERK1/2 and PI3K pathways, but not JNK and p38 pathways, are activated, which is consistent with the results of most previous work.

A relevant question was which molecules are involved under the MAPK/ERK $1 / 2$ and PI3K pathways when CCL24 promotes the proliferation, viability and invasiveness of trophoblasts. In cell cycle, Ki67 is present during all active phases but absent in resting phase, so the expression of Ki67 protein in human cells is strictly related to cell proliferation (Ali et al. 2012). Bcl-2 inhibits apoptosis of cells but, paradoxically, it also suppresses proliferation (Zinkel et al. 2006). Our results in the current study revealed a high expression of Ki67 in trophoblasts, and MAPK/ERK1/2 and PI3K pathways could increase its expression. However, no significant regulation of $\mathrm{BCl}-2$ was observed. Thus, $\mathrm{CCL} 24$ regulates the proliferation of trophoblasts might be Ki67mediated, but not $\mathrm{Bcl}-2$. In addition, we investigated the possible molecules under the MAPK/ERK1/2 and PI3K pathways that might induce the invasion of 


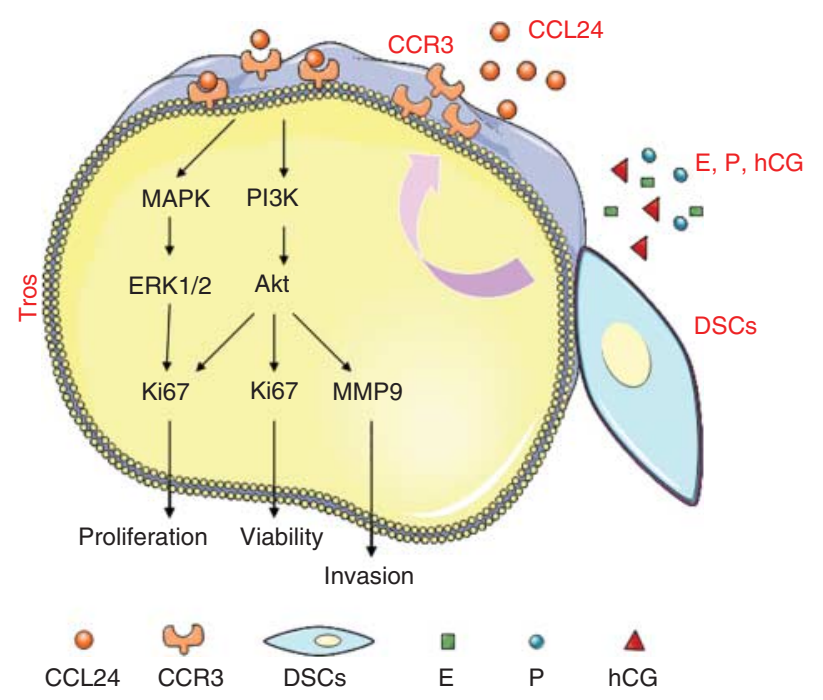

Figure 6 A schematic model of CCL24 promotes the proliferation, viability and invasiveness of trophoblasts. Trophoblasts co-express chemokine CCL24 and receptor CCR3 at the maternal-fetal interface. Trophoblasts-derived CCL24 promotes the expression of Ki67 and MMP9 via MAPK/ERK1/2 or PI3K signaling pathways, and consequently induces the proliferation, viability and invasiveness of trophoblasts. The specific environment in human early pregnant uterus: direct contact with DSCs as well as high concentration of P and hCG regulate the expression of CCL24/CCR3 on trophoblasts, and might amplify trophoblast's self-regulation. Thus, trophoblasts might mediate their own biological functions through CCL24/CCR3 axis, and finally participate in controlling embryo implantation and placentation. DSCs, decidual stromal cells; Tros, trophoblasts; E, 17 $\beta$-estradiol; $\mathrm{P}$, progesterone; $\mathrm{hCG}$, human chorionic gonadotropin.

trophoblasts. MMP9 is an enzyme that could degrade the extracellular matrix in the process of cell migration and invasion, while TIMP1 is a natural inhibitor of it (Yamamoto et al. 2015). MMP9 was previously found as a downstream molecule of chemokines, and acted to increase the invasiveness of trophoblasts (Chen et al. 2011, Zhang et al. 2013). Consistent with these reports, the present work showed that MMP9 is regulated by PI3K signaling pathway when CCL24 promotes the invasion of trophoblasts. However, even though we found the MAPK/ERK1/2 pathway could influence MMP9, we did not observe its effect on regulating the invasiveness of trophoblasts. Therefore, other factors may inhibit the function of MAPK/ERK1/2 signal. Although trophoblasts are rich in TIMP1, we did not find out any pathways that mediate its expression in this study. Actually, the extent of trophoblast invasion is accurately regulated in normal pregnancy. Uncontrolled invasion is related to choriocarcinoma, while invasiveness deficiency could result in abortion, preeclampsia, FGR and so on (Kwak-Kim et al. 2010, Kinoshita et al. 2012). In our current study, CCL24/ CCR3 signal regulates MMP9 level, but does not influence TIMP1 level of trophoblasts. However, other factors at the maternal-fetal interface, such as CD82 (Li et al. 2010), can control trophoblasts invasion through up-regulating TIMP1 expression. The balance of MMP9/TIMP1 constructed by maternal-fetal microenvironment plays an important role in maintaining a status of moderate invasion. However, the mechanism also needs to be further researched.

Collectively, as shown in Fig. 6, the present study for the first time demonstrates chemokine CCL24 as an important mediator in the self-regulating process of trophoblasts. Trophoblasts-derived CCL24 promotes the expression of Ki67 and MMP9 via MAPK/ERK1/2 and or PI3K signaling pathways, and consequently induces the proliferation, viability and invasiveness of trophoblasts. The specific environment in human early pregnant uterus: direct contact with DSCs as well as high concentration of $\mathrm{P}$ and hCG regulate the expression of CCL24/CCR3 on trophoblasts, and might amplify trophoblast's self-regulation. These findings contribute to our understanding about the complex process of embryo implantation, and may provide a clue for searching effective treatment to pregnancy complications.

\section{Supplementary data}

This is linked to the online version of the paper at http://dx.doi. org/10.1530/REP-15-0119.

\section{Declaration of interest}

The authors declare that there is no conflict of interest that could be perceived as prejudicing the impartiality of the research reported.

\section{Funding}

This study was supported by the National Basic Research Program of China (2015CB943300), Major Program of National Natural Science Foundation of China (NSFC) 81490744, and Key Project of Shanghai Basic Research Grant 12JC1401600 (all to D J Li); NSFC 81471513, Training Program for young talents of Shanghai Health System XYQ2013104 and Program for Zhuoxue of Fudan University (all to M Q Li); Research Program for Excellent PhD Candidates of Fudan University (to H Li).

\section{References}

Ali HR, Dawson SJ, Blows FM, Provenzano E, Leung S, Nielsen T, Pharoah PD \& Caldas C 2012 A Ki67/BCL2 index based on immunohistochemistry is highly prognostic in ER-positive breast cancer. Journal of Pathology 226 97-107. (doi:10.1002/path.2976)

Bukovsky A, Cekanova M, Caudle MR, Wimalasena J, Foster JS, Henley DC \& Elder RF 2003 Expression and localization of estrogen receptoraprotein in normal and abnormal term placentae and stimulation of trophoblast differentiation by estradiol. Reproductive Biology and Endocrinology 1 1-18. (doi:10.1186/1477-7827-1-1)

Carosella ED, Moreau P, Lemaoult J \& Rouas-Freiss N 2008 HLA-G: from biology to clinical benefits. Trends in Immunology 29 125-132. (doi:10.1016/j.it.2007.11.005)

Cha J, Sun X \& Dey SK 2012 Mechanisms of implantation: strategies for successful pregnancy. Nature Medicine 12 1754-1767. (doi:10.1038/ nm.3012) 
Chau SE, Murthi P, Wong MH, Whitley GS, Brennecke SP \& Keogh RJ 2013 Control of extravillous trophoblast function by the eotaxins CCL11, CCL24 and CCL26. Human Reproduction 28 1497-1507. (doi:10.1093/ humrep/det060)

Chen JZ, Wong MH, Brennecke SP \& Keogh RJ 2011 The effects of human chorionic gonadotrophin, progesterone and oestradiol on trophoblast function. Molecular and Cellular Endocrinology 342 73-80. (doi:10.1016/j.mce.2011.05.034)

Chen JZ, Sheehan PM, Brennecke SP \& Keogh RJ 2012 Vessel remodelling, pregnancy hormones and extravillous trophoblast function. Molecular and Cellular Endocrinology 349 138-144. (doi:10.1016/j.mce.2011.10.014)

Cory S \& Adams JM 2002 The Bcl2 family: regulators of the cellular lifeor-death switch. Nature Reviews. Cancer 9 647-656. (doi:10.1038/ nrc883)

Erlebacher A 2013 Immunology of the Maternal-Fetal Interface. Annual Review of Immunology 31 387-411. (doi:10.1146/annurev-immunol032712-100003)

Godbole G, Suman P, Gupta SK \& Modi D 2011 Decidualized endometrial stromal cell derived factors promote trophoblast invasion. Fertility and Sterility 95 1278-1283. (doi:10.1016/j.fertnstert.2010.09.045)

Halasz M \& Szekeres-Bartho J 2013 The role of progesterone in implantation and trophoblast invasion. Journal of Reproductive Immunology 97 43-50. (doi:10.1016/j.jri.2012.10.011)

He YY, He XJ, Guo PF, Du MR, Shao J, Li MQ \& Li DJ 2012 The decidual stromal cells-secreted CCL2 induces and maintains decidual leukocytes into Th2 bias in human early pregnancy. Clinical Immunology $\mathbf{1 4 5}$ 161-173. (doi:10.1016/j.clim.2012.07.017)

Huang Y, Zhu XY, Du MR, Wu X, Wang MY \& Li DJ 2006 Chemokine CXCL16, a scavenger receptor, induces proliferation and invasion of firsttrimester human trophoblast cells in an autocrine manner. Human Reproduction 21 1083-1091. (doi:10.1093/humrep/dei436)

Jaleel MA, Tsai AC, Sarkar S, Freedman PV \& Rubin LP 2004 Stromal cell-derived factor-1 (SDF-1) signalling regulates human placental trophoblast cell survival. Molecular Human Reproduction 10 901-909. (doi:10.1093/molehr/gah118)

Jovanovic M, Stefanoska I, Radojcic L \& Vicovac L 2010 Interleukin-8 (CXCL8) stimulates trophoblast cell migration and invasion by increasing levels of matrix metalloproteinase (MMP)2 and MMP9 and integrins 5 and 1. Reproduction 139 789-798. (doi:10.1530/REP-09-0341)

Kinoshita Y, Furuta K, Ishimura N \& Ishihara S 2012 Elevated plasma cytokines in Japanese patients with eosinophilic esophagitis and gastroenteritis. Digestion 86 238-243. (doi:10.1159/000341421)

Kuang H, Chen Q, Fan X, Zhang Y, Zhang L, Peng H, Cao Y \& Duan E 2009 CXCL14 inhibits trophoblast outgrowth via a paracrine/autocrine manner during early pregnancy in mice. Journal of Cellular Physiology 221 448-457. (doi:10.1002/jcp.21877)

Kwak-Kim J, Park JC, Ahn HK, Kim JW \& Gilman-Sachs A 2010 Immunological modes of pregnancy loss. American Journal of Reproductive Immunology 63 611-623. (doi:10.1111/j.1600-0897.2010.00847.x)

Li MQ, Hou XF, Shao J, Tang CL \& Li DJ 2010 The DSCs-expressed CD82 controls the invasiveness of trophoblast cells via integrin $31 / \mathrm{MAPK} /-$ MAPK3/1 signaling pathway in human first-trimester pregnancy. Biology of Reproduction 82 968-979. (doi:10.1095/biolreprod.109.080739)

Li MQ, Tang CL, Du MR, Fan DX, Zhao HB, Xu B \& Li DJ 2011 CXCL12 controls over-invasion of trophoblasts via upregulating CD82 expression in DSCs at maternal-fetal interface of human early pregnancy in a paracrine manner. International Journal of Clinical and Experimental Pathology 4 276-286.

Li MQ, Li HP, Meng YH, Wang XQ, Zhu XY, Mei J \& Li DJ 2012 Chemokine CCL2 enhances survival and invasiveness of endometrial stromal cells in an autocrine manner by activating Akt and MAPK/Erk $1 / 2$ signal pathway. Fertility and Sterility 97 919-929. (doi:10.1016/j. fertnstert.2011.12.049)

Li H, Huang YH, Li MQ, Meng YH, Chen X, Shao J, Tang CL, Du MR, Jin LP \& Li DJ 2013 Trophoblasts-derived chemokine CCL24 promotes the proliferation, growth and apoptosis of decidual stromal cells in human early pregnancy. International Journal of Clinical and Experimental Pathology 6 1028-1037.

Munn DH, Zhou M, Attwood JT, Bondarev I, Conway SJ, Marshall B, Brown C \& Mellor AL 1998 Prevention of allogeneic fetal rejection by tryptophan catabolism. Science 281 1191-1193. (doi:10.1126/science. 281.5380.1191)
Oreshkova T, Dimitrov R \& Mourdjeva M 2012 A cross-talk of decidual stromal cells, trophoblast, and immune cells: a prerequisite for the success of pregnancy. American Journal of Reproductive Immunology $\mathbf{6 8}$ 366-373. (doi:10.1111/j.1600-0897.2012.01165.x)

Owczarek W, Paplinska M, Targowski T, Jahnz-Rozyk K, Paluchowska E, Kucharczyk A \& Kasztalewicz B 2010 Analysis of eotaxin 1/CCL11, eotaxin 2/CCL24 and eotaxin 3/CCL26 expression in lesional and nonlesional skin of patients with atopic dermatitis. Cytokine 50 181-185. (doi:10.1016/j.cyto.2010.02.016)

Paiva P, Hannan NJ, Hincks C, Meehan KL, Pruysers E, Dimitriadis E \& Salamonsen LA 2011 Human chorionic gonadotrophin regulates FGF2 and other cytokines produced by human endometrial epithelial cells, providing a mechanism for enhancing endometrial receptivity. Human Reproduction 26 1153-1162. (doi:10.1093/humrep/der027)

Park DW \& Yang KM 2011 Hormonal regulation of uterine chemokines and immune cells. Clinical and Experimental Reproductive Medicine 38 179-185. (doi:10.5653/cerm.2011.38.4.179)

Rizzo R, Melchiorri L, Stignani M \& Baricordi OR 2007 HLA-G expression is a fundamental prerequisite to pregnancy. Human Immunology 68 244-250. (doi:10.1016/j.humimm.2006.10.012)

Shamri R, Young KM \& Weller PF 2013 PI3K, ERK, p38 MAPK and integrins regulate CCR3-mediated secretion of mouse and human eosinophilassociated RNases. Allergy 68 880-889. (doi:10.1111/all.12163)

Szekeres-Bartho J, Halasz M \& Palkovics T 2009 Progesterone in pregnancy; receptor-ligand interaction and signaling pathways. Journal of Reproductive Immunology 83 60-64. (doi:10.1016/j.jri. 2009.06.262)

Timeva T, Shterev A \& Kyurkchiev S 2014 Recurrent implantation failure: the role of the endometrium. Journal of Reproduction \& Infertility $\mathbf{1 5}$ 173-183.

van Meerloo J, Kaspers GJ \& Cloos J 2011 Cell sensitivity assays: the MTT assay. Methods in Molecular Biology 731 237-245. (doi:10.1007/978-161779-080-5_20)

Vinader V \& Afarinkia K 2012 A beginner's guide to chemokines. Future Medicinal Chemistry 4 845-852. (doi:10.4155/fmc.12.49)

Wallace AE, Cartwright JE, Begum R, Laing K, Thilaganathan B \& Whitley GS 2013 Trophoblast-induced changes in C-x-C motif chemokine 10 expression contribute to vascular smooth muscle cell dedifferentiation during spiral artery remodeling. Arteriosclerosis, Thrombosis, and Vascular Biology 33 e93-e101. (doi:10.1161/ATVBAHA.112.300354)

Wang Y, Zhang Y, Li MQ, Fan DX, Wang XH, Li DJ \& Jin LP 2014 Interleukin-25 induced by human chorionic gonadotropin promotes the proliferation of decidual stromal cells by activation of JNK and AKT signal pathways. Fertility and Sterility 102 257-263. (doi:10.1016/ j.fertnstert.2014.03.025)

Yamamoto K, Murphy G \& Troeberg L 2015 Extracellular regulation of metalloproteinases. Matrix Biology 44-46 255-263. (doi:10.1016/j. matbio.2015.02.007)

Zhang Y, Li HY, Zhang ZH, Bian HL \& Lin G 2014 Garlic-derived compound S-allylmercaptocysteine inhibits cell growth and induces apoptosis via the JNK and p38 pathways in human colorectal carcinoma cells. Oncology Letters 8 2591-2596. (doi:10.3892/ol.2014.2579)

Zhebrun DA, Totolyan AA, Maslyanskii AL, Titov AG, Patrukhin AP, Kostareva AA \& Gol'Tseva IS 2014 Synthesis of some CC chemokines and their receptors in the synovium in rheumatoid arthritis. Bulletin of Experimental Biology and Medicine 158 192-196. (doi:10.1007/ s10517-014-2720-9)

Zinkel S, Gross A \& Yang E 2006 BCL2 family in DNA damage and cell cycle control. Cell Death and Differentiation 13 1351-1359. (doi:10.1038/sj.cdd.4401987)

Zlotnik A \& Yoshie O 2012 The chemokine superfamily revisited. Immunity 36 705-716. (doi:10.1016/j.immuni.2012.05.008)

Received 17 March 2015

First decision 7 April 2015

Revised manuscript received 22 August 2015

Accepted 27 August 2015 